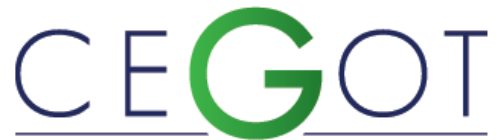

Centro de Estudos de Geografia e Ordenamento do Território
Geografia e Ordenamento do Território, Revista Eletrónica Centro de Estudos de Geografia e Ordenamento do Território http://cegot.org

ZECHIN, PATRICK

Universidade Estadual de Goiás, Departamento de Arquitetura e Urbanismo

74.140-140. Rua Riu Brasil Cavalcante, 421. Edifício Visage Oeste, apartamento 2403. Setor Oeste, Goiânia - Brasil

Patrick.zechin@gmail.com

Holanda, FREDERICO

Universidade de Brasília, Faculdade de Arquitetura e

Urbanismo

73.105-907. Condomínio Vivendas Colorado 1, módulo J, casa 1. Brasília -

Brasil

Fredholanda44@gmail.com

\title{
A dimensão espacial da desigualdade socioeconômica
}

The socioeconomic inequality and its spatial dimension

Referência: Zechin, Patrick; Holanda, Frederico (2018). A dimensão espacial da desigualdade socioeconômica. Revista de Geografia e Ordenamento do Território (GOT), n. ${ }^{\circ} 13$ (junho). Centro de Estudos de Geografia e Ordenamento do Território, p. 459-485, dx.doi.org/10.17127/got/2018.13.020

\section{RESUMO}

Nos últimos anos, o Brasil conheceu algum progresso no que diz respeito à diminuição da desigualdade socioeconômica, mas, embora a desigualdade tenha recuado um pouco, a segregação entre as classes mais altas e as mais baixas não pareceu ter conhecido melhora e o ambiente urbano brasileiro continua sendo um lugar de exclusão para um importante contingente populacional. Considerando que é essencial o conhecimento mais pormenorizado da dinâmica da desigualdade espacial para a formulação de melhores políticas públicas, objetivamos, por meio do uso de técnicas de análise espacial alternativas ao tradicional Índice de Dissimilaridade (D), apresenta-se e discute-se a relação entre espaço e desigualdade nas cinco cidades mais desiguais do país, buscando matizes mais detalhadas da materialização da segregação espacial.

Palavras-chave: Desigualdade, segregação, espacialização, análise espacial.

\section{ABSTRACT}

In recent years Brazil had met some decrease of inequality indexes. Albeit it has decreased segregation has been a steady condition for the many in our society. Whereas the more accurate data is essential to the formulation of public policies which can take into account the space and inequality relationship the paper aims to present, analyse and compare, using alternative spatial analysis techniques to Dissimilarity index (D), to study of socioeconomic inequality in the most socially and economically contrasted cities of Brazil.

Keywords: Inequality, segregation, spatialization, spatial analysis. 


\section{Introdução}

É premente compreender melhor a desigualdade social brasileira particularmente persistente e a segregação espacial a ela atrelada. O reconhecimento da importância da questão da desigualdade em nossa sociedade faz com que, historicamente, uma parte das políticas públicas desenvolvidas pelo Estado brasileiro nos três níveis seja, de alguma forma, em maior ou menor grau, esteja relacionada a problemas decorrentes da desigualdade socioeconômica. Embora também tenhamos períodos em que o acirramento de políticas de cunho neoliberal, como aqueles que se sucederam nos anos 1990 ou o atual momento, implique em retrocessos nestas políticas.

Nos últimos anos, observamos, no Brasil, ao menos no período de governos pós-neoliberais liderados pelo Partido dos Trabalhadores (2003 - 2016), a redução acentuada do número de famílias situadas abaixo da linha da pobreza e alguma diminuição da desigualdade socioeconômica. Entretanto, a redução não é medida por uma linha arbitrária de rendimentos na qual estão situados os pobres, mas, antes, pelas distâncias entre as posições relativas ocupadas pelos diversos segmentos da sociedade.

As distâncias continuam altas no Brasil e são fruto de um processo econômico e social desenvolvido desde o período colonial que engendrou no país uma dinâmica já chamada de modernização conservadora. As cidades brasileiras são evidências notáveis deste processo, conforme discutido por Maricato (2002), principalmente através do exemplo da construção de moradia (e parte da cidade) pelos próprios moradores, em regra de baixa renda, em seus horários de folga, ao longo de muitos anos, ao largo de toda e qualquer legislação urbanística, muitas vezes em áreas ocupadas ilegalmente.

Essa prática de autoconstrução de habitação ilegal foi explicada por Oliveira (2003) como uma espécie de produção doméstica pela população mais pobre das cidades que ao construir sua própria casa sem a confluência de conhecimento técnico de arquitetura ou engenharia, sem financiamento formal ou respeito à legislação fundiária, urbanística e edilícia é fundamental para o barateamento da força de trabalho uma vez que o custo da moradia não estava incluído no salário. 
A autoconstrução, ainda segundo Oliveira, contribui para a acumulação capitalista durante o período de industrialização do Brasil, principalmente entre 1940 e 1980 e a esta industrialização de baixos salários correspondeu uma urbanização com baixos salários, conforme demonstrado por Maricato (2002). Este processo revela uma certa modernização e um certo desenvolvimento que dependeram de práticas pré-capitalistas (a autoconstrução) para a produção de uma parte importante da cidade brasileira. Tal imbricação foi e ainda é fundamental para o processo de acumulação nacional.

Desta maneira, temos um vislumbre de como o crescimento urbano brasileiro sempre se deu com exclusão social e mesmo o acentuado crescimento econômico brasileiro em grande parte do século XX não implicou em modificação (mesmo que tímida) na forte desigualdade social. Ao contrário, o impacto do declínio econômico nas décadas de 1980 e 1990 sobre uma sociedade já desigual aprofundou a exclusão social com uma maior concentração de renda. Dados da Pesquisa Nacional por Amostragem de Domicílio Contínua (PNAD Contínua) do IBGE (Instituto Brasileiro de Geografia e Estatística) indicam que em 2017 10\% mais ricos dos brasileiros detinham $43,3 \%$ da riqueza produzida pelo país; enquanto os $10 \%$ mais pobres detinham $0,7 \%$ das riquezas.

Essa desigualdade não surge apenas da reestruturação produtiva pela qual o capitalismo passa a partir de meados da década de 1970, mas trata-se de um aprofundamento da desigualdade numa sociedade já desigual. Neste país que ao se modernizar, conforme apontado por Maricato (2002), não superou alguns traços dos períodos colonial, imperial e da primeira república elitista, marcados pela concentração de terra, renda e poder, o Estado pouco foi além de em um instrumento da elite que, entre outras dinâmicas, desenvolve uma aplicação enviesada da lei para manutenção de poder concentrado e privilégios nas cidades refletindo e, ao mesmo tempo, promovendo a segregação no território urbano.

A segregação urbana, marca da desigualdade engendrada nas cidades brasileiras desenvolvidas em um contexto específico de capitalismo periférico, foi promovida pelos extratos mais privilegiados da sociedade para favorecer sua própria reprodução social ao disputar localidades capazes de comprimir seus tempos e espaços de deslocamento de modo a dispor dos sistemas de recursos urbanos (melhores empregos, saúde, cultura, educação, consumo, lazer etc.) de maneira mais eficiente, nos moldes do que foi estudado por Villaça (2007). 
Neste estudo, nosso objeto é a relação da desigualdade socioeconômica com o espaço urbano manifestada na segregação muito marcada de duas classes sociais diametralmente opostas no espaço das cinco cidades mais desiguais do país. Entendemos que os padrões que emergem podem ajudar a compreender melhor a circunstância não exclusivamente socioeconômica, mas também profundamente espacial contida na evolução urbana particular de cada cidade da segregação enquanto manifestação de suas desigualdades.

Precisamos, contudo, esclarecer que alguns pesquisadores criticam o uso do conceito de segregação, alegando que ele diz respeito a contextos históricos e nacionais bem delimitados, como no caso da espacialização da moradia dos negros nos EUA e, portanto, a utilização do conceito faria mais sentido quando associado a questões de separação de grupos raciais ou étnicos.

Tal argumento busca a precisão do conceito aplicado a um caso particular de espacialização da desigualdade socioeconômica. Todavia, o termo conduz tal força de denúncia das mazelas sociais que se torna particularmente útil para a situação limite da cidade brasileira podendo, acreditamos, também ser utilizado como categoria explicativa do processo de urbanização brasileiro.

Entendemos que as peculiaridades da evolução das cidades brasileiras desde os tempos da colônia, aliadas à dinâmica social excludente intrinsecamente ligada aos efeitos persistentes da escravidão (não se tem $60 \%$ de sua história atrelada à escravidão impunemente) nos fazem crer que há que se falar de um padrão de segregação espacial brasileiro, quando este conjuga, em graus variados, em nosso entender, os atributos espaciais da fragmentação, dispersão e da periferização.

A desigualdade se manifesta concretamente nas cidades na forma de espaços fragmentados morfologicamente, em relação ao acesso de grandes contingentes populacionais às correntes de produção e consumo de bens e serviços tipicamente associados com o nosso modo de vida urbano contemporâneo. Estes espaços urbanos mal conectados uns aos outros e ao, digamos, tecido principal e mais contínuo implicam um duplo sentido: (i) de impacto direto na compressão do tempo e do espaço, essenciais em ambientes urbanos dominados pela necessidade de circulação eficiente e (ii) de sintoma da divisão social, que distribui desigualmente as oportunidades, os espaços e liberdades entre seus habitantes. 
A dinâmica da produção do espaço urbano das grandes cidades brasileiras produz uma dimensão cotidiana da vida urbana que diferencia, a partir da moradia, modos de uso do espaço, que produz cidades que negam à totalidade dos indivíduos uma forma superior de direito, na condição de direito à cidade nos termos apontados por Lefebvre (2011), ou seja, na condição ao direito à liberdade, à individualização na socialização, ao habitat e à habitação.

Deste modo, as questões que levantamos aqui podem contribuir no esforço da explicação da segregação espacial das classes sociais pelo viés do espaço, que foge da corrente principal de estudos urbanos no Brasil, que privilegia as implicações socioeconômicas, como também podem fornecer subsídios para discussões no âmbito do desenvolvimento de políticas públicas, no sentido de que elas levem em consideração o efeito do ambiente já construído nas dinâmicas sociais ao invés de considerar, muitas vezes, o espaço como um simples e inerte palco no qual a vida social se desenvolve.

O nosso interesse ao estudarmos os dados referentes à espacialização de diferentes grupos nas cidades é saber quão concentrado ou disperso espacialmente são os atributos de pobreza ou de riqueza em uma dada área urbana, para, em seguida, averiguarmos essas áreas urbanas sob uma lente morfológica. Para tanto, utilizaremos ferramentas de espacialização dos dados oficiais sobre a renda como forma de apresentar matizes mais detalhadas da segregação, que escapam das limitações de índices mais comumente utilizados, como o Índice de Dissimilaridade (D), desenvolvido ainda na década de 1950 e que inaugura uma linha tradicional de estudos de segregação. São utilizadas, para tanto, as bases vetoriais disponibilizadas pelo IBGE e os dados do Censo de 2010.

O estudo da segregação espacial enquanto dimensão tangível da desigualdade socioeconômica brasileira tem sido objeto de estudo de diversos autores tendo em vista a importância do tema na vida cotidiana do país e acreditamos que a compreensão desta dinâmica social pode ser incrementada na medida em que os estudos levem em consideração a interação de dois elementos básicos como exemplifica Ramos (2002): (i) um conjunto de conceitos e teorias que caracterizam os fenômenos que atuam no espaço urbano, seus padrões, causas e implicações e (ii) métodos, técnicas quantitativas de representação e análise do objeto de estudo em questão. Certamente, avançamos quando fazemos convergir os dois elementos, o que permite o refinamento de conceitos já 
estudados por diversos pesquisadores em todo o mundo, embora não seja a intenção deste estudo sistematizar e problematizar tais estudos.

Uma ampla variedade de medidas é utilizada para estimar a manifestação da desigualdade socioeconômica e a segregação espacial dela resultante na cidade, região ou mesmo país, sendo que as mais frequentemente usadas são ligadas às desigualdades de renda e consumo. E embora haja críticas ao peso dado à renda na abordagem do tema da desigualdade, será este o dado utilizado no estudo, uma vez que este foi o critério utilizado pelo relatório State of the world' cities 2010/2011 (2012), produzido pela ONU-Habitat, para ranquear diversas cidades do mundo subdesenvolvido de modo a aferir as cidades mais desiguais do mundo. O relatório aponta cinco cidades brasileiras entre as mais desiguais do mundo, considerando o coeficiente de Gini: Goiânia, Fortaleza, Belo Horizonte, Brasília e Curitiba, nesta ordem. As cidades brasileiras aparecem após de um pequeno grupo de cidades sul africanas, apresentando um coeficiente de Gini que varia de 0,65 para Goiânia e 0,59 para Curitiba.

\section{Segregação Urbana}

A segregação urbana entre classes sociais pode ser assumida como a mais importante manifestação espacial da desigualdade de renda, desde logo entre ricos e pobres, que de acordo com Villaça (2007) deve ser analisada levando-se em conta as regiões da cidade e não seus bairros de forma separada.

No que diz respeito à relação da segregação residencial com as classes sociais no espaço urbano, podemos recorrer a Correa (2013) para compreender como os estudos em geral têm abordado a questão. Essa abordagem considera a segregação, de um lado, como autossegregação e, de outro, como segregação imposta e segregação induzida. Em comum está uma política de classe que gera esses tipos de segregação.

A autossegregação, de acordo ainda com o autor, é uma política de classe associada à elite e aos estratos superiores da classe média, dotados de elevada renda monetária, visando reforçar diferenciais de existência e de condições de reprodução dos grupos por intermédio 
da escolha das melhores localizações no espaço urbano, tornando-as exclusivas em razão dos elevados preços da terra urbana, por exemplo. No caso dos condomínios fechados de perfil popular, não há que se falar em escolha das melhores localizações, uma vez que se trata mais de tentativa de mimetização de uma tipologia e de um certo padrão de consumo associado às classes mais abastadas e que, em regra, são implementadas em localizações tão precárias quantos os demais bairros das classes subalternas.

O autor defende ser tênue o limite entre a segregação imposta e a induzida, com o segundo grupo tendo à sua disposição alguma escolha possível. As diferenças entre as espacialidades das áreas segregadas manifestam-se por meio da concentração, em cada uma, de um grupo social dotado de relativa homogeneidade, que materializa sua existência não apenas material, mas também simbólica, afetiva e cultural e a reproduz. As áreas segregadas estariam dispostas de acordo com uma lógica espacial variável, que as inscrevem no espaço urbano, gerando padrões espaciais de segregação residencial.

Villaça (2007) realiza estudo clássico e pioneiro quanto ao espaço urbano das cidades brasileiras e que orienta uma grande quantidade de estudos posteriores. Sua tese é que os processos que envolvem as cidades enquanto partícipes da estruturação da rede urbana (processo regional, nacional ou planetário) não seguem a mesma lógica e não passam pelas mesmas mediações dos processos que regem a estruturação interna dos espaços urbanos. Para ele, tais mediações passam, fundamentalmente, pelos "traços nacionais definidores da estrutura e dos conflitos de classe e, ainda, pela dominação política e econômica através do espaço intraurbano" (Vilaça, 2007). Os traços se manifestam na estrutura espacial urbana por meio da segregação, que passa a ser, na visão do autor, o processo central definidor dessa estrutura. A distinção mais importante entre um tipo de espaço e outro deriva dos transportes e da comunicação.

Segue-se a essa distinção a seguinte hipótese: para se estudar a estruturação urbana, é preciso se concentrar na circulação das pessoas enquanto consumidores ou, no máximo, enquanto vendedores da capacidade de trabalho e não na circulação do capital em qualquer uma de suas formas. Portanto, os transportes intraurbanos são os maiores responsáveis pela valorização daquilo que chama de "ponto", uma vez que a implantação de uma via regional, por exemplo, tem o efeito primário de melhorar a sua acessibilidade e, consequentemente, valorização. 
Outro aspecto interessante diz respeito à compressão dos tempos de deslocamento enquanto objetivo da luta pelo espaço urbano. Essa luta passa pela concentração das melhores oportunidades nas grandes cidades, que, em sua maioria, estão concentrados nos centros das cidades. No caso dos mais pobres, as oportunidades mais disputadas são os empregos, que, em regra, estão no setor terciário da economia e têm que ser buscadas, pelos mais pobres, de vários pontos da cidade o que implica que a localização de suas moradias e a capacidade de acesso destes aos centros são elementos fundamentais na sua inserção nos circuitos principais da economia urbana.

Torna-se evidente que a questão do domínio dos tempos de deslocamento é vital. Um ponto central no estudo é a irreprodutibilidade da localidade: o resultado da produção do espaço urbano é a localização, que é única, e é ela que especifica uma determinada parte da cidade e como esta se relaciona com o sistema como um todo, e não o conjunto de objetos urbanos como praças ou ruas etc.

Estudos conduzidos por Ribeiro Lago (apud Villaça, 2007) apontam na promoção imobiliária o elemento de ligação entre as grandes transformações macroeconômicas e a restruturação urbana. Esta última é provocada pelos lucros das atividades incorporadoras derivadas de transformações do uso do solo. Ribeiro Lago chega a considerar a moderna atividade de incorporação a causadora da segregação espacial típica das grandes cidades de países industrializados da periferia do sistema capitalista, como o Brasil.

Embora as conclusões de estudos como os de Villaça e Ribeiro Lago sejam acertadas, nossas análises mostrarão que a segregação não pode ser entendida de modo uniforme como resultado apenas de dinâmicas socioeconômicas impermeáveis a outros fatores que, em nosso entender, podem ser tão importantes quanto estes. A especificidade, em cada cidade, da área concentradora da população mais pobre também é fruto de outras questões como a morfológica ou a histórica, o que acentua o caráter processual desta dinâmica social ao mesmo tempo que aponta para a inexistência de soluções simples para o problema. 


\section{Medições do Espaço}

Recorrer a representações abstratas das cidades para melhor pensá-las não é novidade na história. Se pensarmos nos esquemas da cidade de Mileto ou as cidades ideais do Renascimento, por exemplo, perceberemos que esse tipo de ação racional ocorreu frequentemente ao pensar-se a organização do espaço urbano.

A necessidade é mais evidente quando nos deparamos com um número cada vez maior de cidades com elevado ritmo de crescimento populacional. A partir de meados do século $X X$, com a popularização e sofisticação dos recursos de informática, a tarefa de abstrair a realidade urbana passa a ganhar cada vez mais destaque. Os modelos computacionais, com o tempo, ocuparam-se de questões cada vez mais complexas como o planejamento de redes de transporte, mapeamento de atividades urbanas ou alocação de usos do solo.

No que diz respeito a este estudo, o uso das técnicas quantitativas de representação e análise serão alimentadas pelos dados disponibilizados pelo Censo 2010 do IBGE, sistematizados quantitativamente e desagregados por setores censitários.

O IBGE trabalha com um ranqueamento de classes sociais baseado na quantidade de salários mínimos auferidos pela família: classe A (renda acima de 20 salários mínimos); classe B (renda variando entre 10 e 20 salários mínimos); classe C (renda variando entre 4 a 10 salários mínimos); classe D (renda variando entre 2 a 4 salários mínimos) e classe E (renda de até 2 salários mínimos).

O sistema de classificação do IBGE é problemático quando aplicado às análises espaciais utilizadas neste estudo, pois não encontra uma correspondência automática com as faixas de renda especializadas de acordo com os dados disponibilizados pelo Censo 2010. Há muita discrepância entre o número de salários mínimos compondo o estrato dos mais ricos entre municípios como Belo Horizonte e Curitiba, por exemplo. Por isso, optamos por dividir os dados em tantas faixas de renda quantas forem necessárias para que ao menos um dos estratos extremos (os mais pobres e os mais ricos) conhecessem números de famílias parecidos.

Neste trabalho, concentramo-nos em dois estratos de renda antípodas. O primeiro está incluso no que o IBGE chama de classe E, mas mesmo dentro dessa classe existem 
diferentes perfis de renda e o estrato que nos interessa é de domicílios particulares com rendimento nominal mensal domiciliar per capita dentro da faixa que vai de mais de $1 / 8$ até 1/4 salario mínimo1, o qual concentra indivíduos na faixa que vai do limite da pobreza extrema ao limite da pobreza, segundo o IBGE, e que também é a faixa de renda alvo do programa do governo federal Bolsa Família; o segundo engloba o grupo composto por domicílios particulares com rendimento nominal mensal domiciliar per capita de mais de 10 salários mínimos.

\section{Indicadores territoriais de segregação espacial}

Nos últimos anos, medidas espaciais vêm sendo cada vez mais utilizadas em análises espaciais dentro de aplicativos SIG. É cada vez mais importante a presença de análises espaciais ancoradas em técnicas de geoinformação com a incorporação de novas funcionalidades para a análise de aspectos espaciais relevantes - por exemplo a relação entre vizinhanças e as características geométricas das unidades de análise (como os setores censitários). Segundo Bailey e Gattrel (1995), o objetivo da análise espacial é aprofundar a compreensão do processo, avaliar evidências de hipóteses a ele relacionadas, ou ainda tentar prever valores em áreas onde as observações não estão disponíveis.

Tais técnicas são conhecidas como Análise Exploratória de Dados Espaciais (AEDE) e podem ser classificadas em univariadas ou multivariadas, dependendo do número de variáveis envolvidas. Neste estudo, a partir das informações colhidas pelo Censo 2010, nos utilizaremos de duas para buscar refinar os dados e avançar na espacialização das classes sociais que nos ocupamos neste trabalho: (i) a Autocorrelação Espacial e (ii) o Método Centrográfico.

\subsection{Autocorrelação espacial}

É a correlação ou similaridade de valores geralmente próximos em um conjunto de dados e que pode ser aferida tanto por métodos globais quanto locais. No caso de dados espaciais, a 
autocorrelação é esperada quando valores medidos de forma próxima no espaço são mais similares que valores medidos distantes um do outro, tendendo à formação de cluster. Uma das técnicas mais utilizadas no estudo de fenômenos espaciais é a análise de autocorrelação espacial, que permite identificar a estrutura de correlação espacial que melhor represente o padrão de distribuição dos dados analisados, ou seja, é o mesmo que dependência espacial cujas características podem ser relacionadas tanto positiva quanto negativamente.

Mitchell (2009) indica que o chamado I de Moran pode ser utilizado para calcular o indicador tanto em um nível local quanto global, indicando que a autocorrelação positiva evidencia a presença de semelhanças entre as variáveis da característica estudada e a sua localização espacial. No caso de autocorrelação contrária, a evidência é de heterogeneidade entre as variáveis estudadas e a sua localização espacial.

Quando o I de Moran resultar em um valor aproximado de 1, concluímos pela presença de autocorrelação positiva (clustering), revelando, assim, similaridade entre os dados da característica estudada, ou seja, as regiões pobres estão propensas a serem rodeadas por regiões vizinhas igualmente pobres e regiões não pobres estão propensas a serem rodeadas por regiões vizinhas igualmente não pobres. Já no caso do valor do I se aproximar de -1 temos autocorrelação negativa, constatando a dissimilaridade entre os valores estudados e a localização espacial do atributo.

Genovez (2002) destaca que o Indicador Local de Associação Espacial 2 executa a decomposição do indicador global de autocorrelação na contribuição local de cada observação em quatro categorias, cada uma individualmente correspondendo a um quadrante de dispersão de Moran, que corresponde a quatro padrões de associação local espacial entre as regiões e seus respectivos vizinhos.

Conforme podemos verificar na figura 1, o diagrama está dividido em 4 quadrantes. No quadrante $\mathrm{HH}$ estão incluídas as regiões que apresentam altos valores para a variável analisada e que estão circundadas por regiões que, igualmente, apresentam altos valores para a variável. O quadrante $\mathrm{LH}$ exibe as regiões com baixos valores para a variável de interesse, cercada por vizinhos que apresentam valores altos para a mesma variável. 0 quadrante LL é constituído por regiões cujos valores para a variável são baixos e estão circundados por outras que igualmente apresentam baixos valores para a variável. Por último, temos o quadrante $\mathrm{HL}$ composto por regiões com altos valores para a variável de interesse e que se encontram circundadas por regiões que apresentam baixos valores para a 
variável. Desta forma, resta claro que apenas as regiões localizadas nos quadrantes HH e LL apresentam dependência entre renda e espaço. Embora, no caso deste estudo, o diagrama de dispersão seja substituído por mapas, o ArcGis utiliza a nomenclatura utilizada no diagrama, o que justifica a breve explicação sobre seu funcionamento.

O cálculo do I de Moran global pode ser observado na tabela 1 . Nela, percebemos a tendência geral de agrupamentos existentes entre as várias faixas de renda para os municípios estudados. Ela também indica a probabilidade de a similaridade entre um determinado setor e sua vizinhança não ser devido ao acaso, através do cálculo do Z-score3 (o escore padronizado). Este coeficiente demonstra a probabilidade de se estar errado ao rejeitar a hipótese de nulidade.

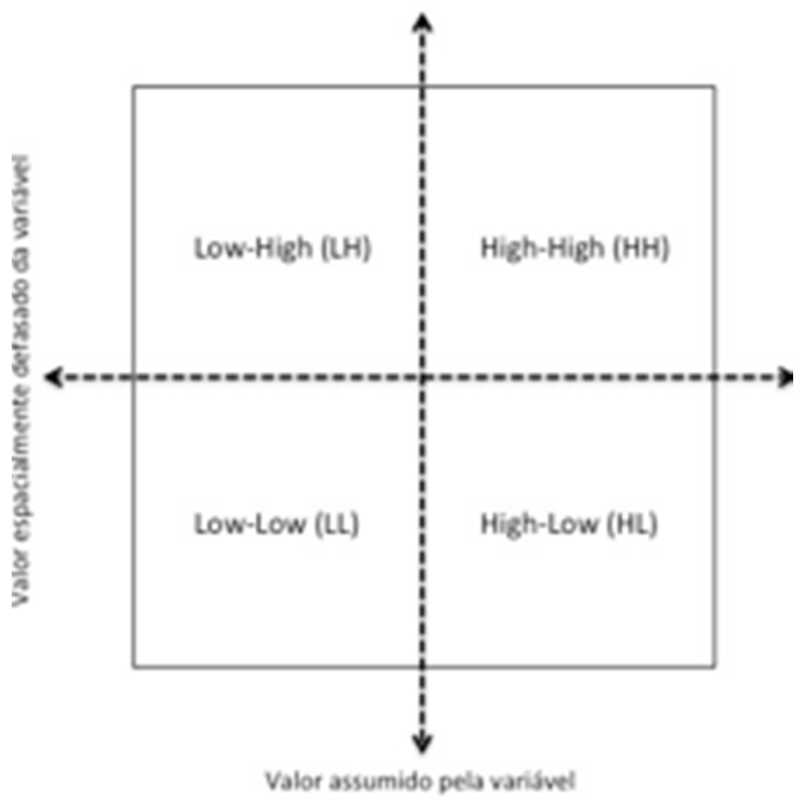

Figura 1 - Esquema explicativo do diagrama de dispersão de Moran.

Da tabela percebemos que, de forma global, os municípios estudados formam clusters referentes aos dados apresentados pela tabela sobre o valor do rendimento nominal médio mensal das pessoas responsáveis por domicílios particulares permanentes (com rendimento), ou seja, há formação de clusters espaciais para o percentual de pessoas muito pobres e muito ricas em todos os municípios estudados. Disso extraímos que os clusters indicam dependência espacial da renda.

30 z-score ajuda a entender onde um determinado escore se encontra em relação aos demais numa distribuição. Indica o quanto acima ou abaixo da média um escore está em termos de unidades padronizadas de desvio, sendo calculado usando a média e o desvio padrão. 


\begin{tabular}{lll}
\hline Município & I de Moran & Z-score \\
\hline Goiânia & 0,169087 & 157,13504 \\
\hline Fortaleza & 0,528401 & 327,428139 \\
Belo Horizonte & 0,500704 & 294,480154 \\
Brasília & 0,388922 & 639,440930 \\
Curitiba & 0,760274 & 236,195787 \\
\hline
\end{tabular}

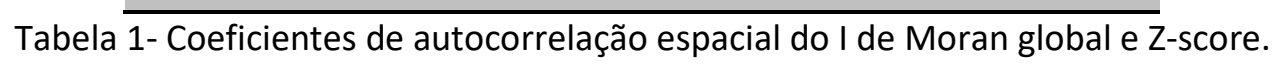
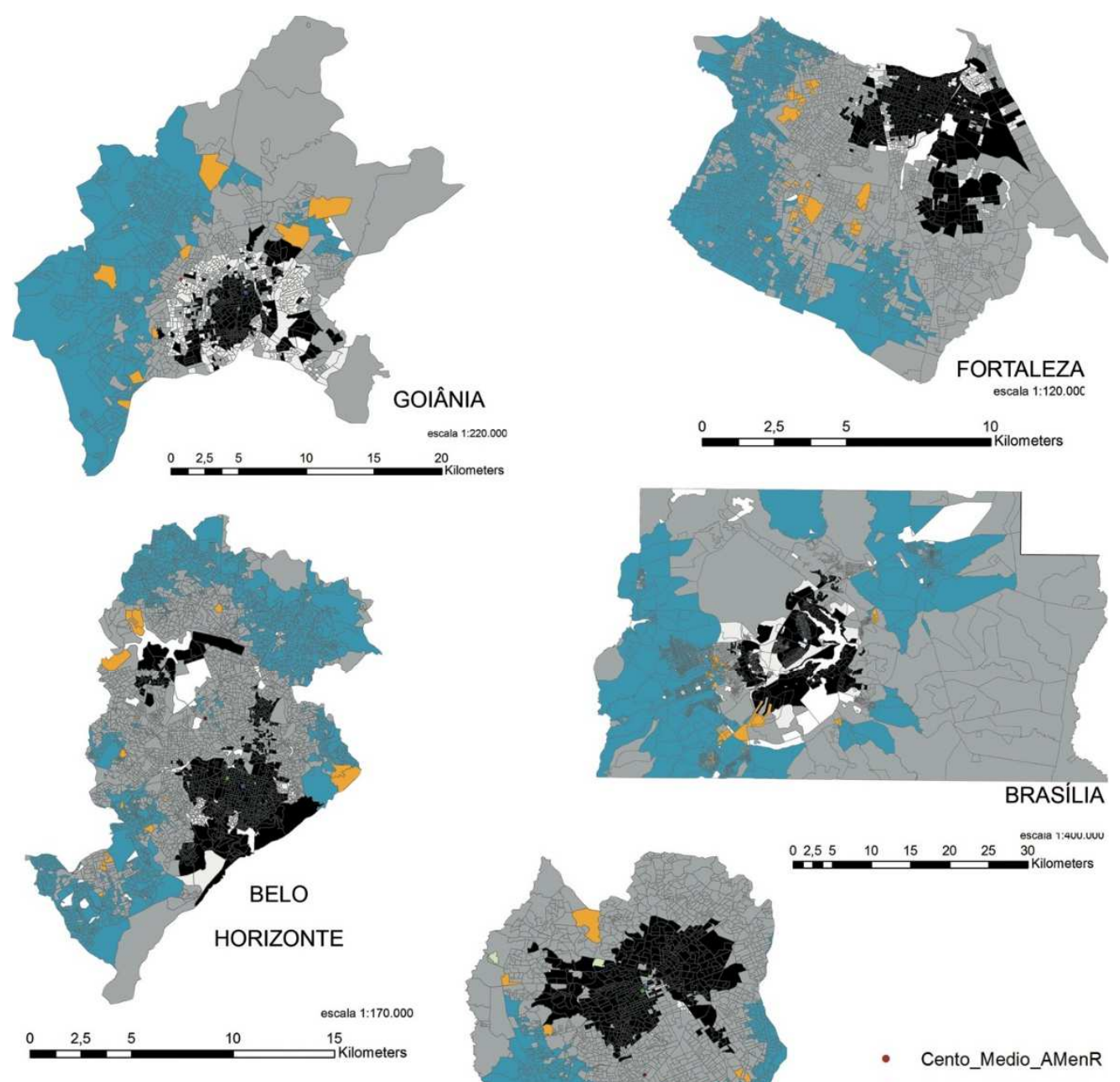

BRASÍLIA

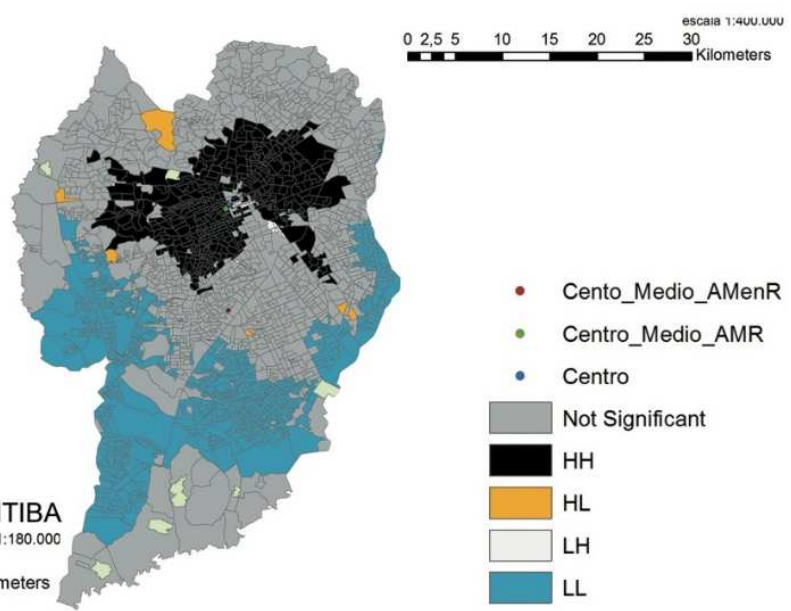

Figura 2 - I de Moran local para as cinco cidades estudadas. 
De forma a estabelecer uma análise mais fina, utilizamos o I de Moran local, que, conforme podemos perceber na figura 2, revela padrões locais de associação espacial, alocando os dados de acordo com os quadrantes apresentados anteriormente, conforme a distribuição do percentual de pessoas muito pobres e muito ricas. Os mapas resultantes dos diagramas de dispersão de Moran demonstram a dispersão da pobreza e da riqueza nos cinco municípios estudados com base no censo 2010, indicando a existência de autocorrelação espacial positiva, ratificando os resultados obtidos pelo / de Moran global.

\subsection{Método Centrográfico}

Greene e Pick (2012) apresentam o método centrográfico4 como uma possibilidade estatística de medir a distribuição espacial de um determinado grupo (tomado como referência) em torno de um ponto central determinando seu estado de concentração ou dispersão. Segundo os autores, esse método pode responder com uma maior precisão a questões sobre qual grupo de renda5 está mais ou menos disperso em uma cidade.

O método centrográfico é baseado em cálculos de centro médio para cada um dos atributos estudados e raio padrão para as áreas de concentração. O raio forma um círculo em volta do centro médio, mostrando quão concentrado ou disperso espacialmente é uma determinada característica. A ponderação é proporcional à concentração do atributo medida em uma coordenada particular. Em análises mais avançadas, o desvio padrão aparece como uma elipse e não como um círculo, de modo que a ponderação do centro médio fornece informações adicionais constantes na orientação direcional da elipse.

Com base nos dados disponibilizados pelo Censo 2010, para os dois grupos de renda de que nos ocupamos, podemos perceber na figura 3, as diferenças na concentração e na direção entre os dois grupos de renda e, assim, como eles se comportam em relação a um dado ponto central em cada cidade6.

A partir destes resultados, percebemos, de início, que, corroborando Villaça (2007), a análise por região é muito mais reveladora do que a análise centrada na escala da residência, do setor censitário tomado individualmente ou do bairro. A distribuição das

4 Centrographic method, em inglês.

$5 \mathrm{Na}$ verdade, o método centrográfico, tal qual um índice de dissimilaridade, mede a igualdade ou uniformidade de quaisquer grupos mutualmente excludentes: pobres e ricos, negros e brancos etc.

6 Neste estudo, indicamos para cada sistema urbano um ponto central referente à localização do marco inicial de construção da cidade. 
elipses relativas aos grupos das Áreas de Menor Rendimento (AMenR) são bastante diferentes umas das outras, o que indica que os atributos espaciais de dispersão e concentração de cada grupo provavelmente são influenciados por condições locais tanto quanto condições estruturais mais gerais.

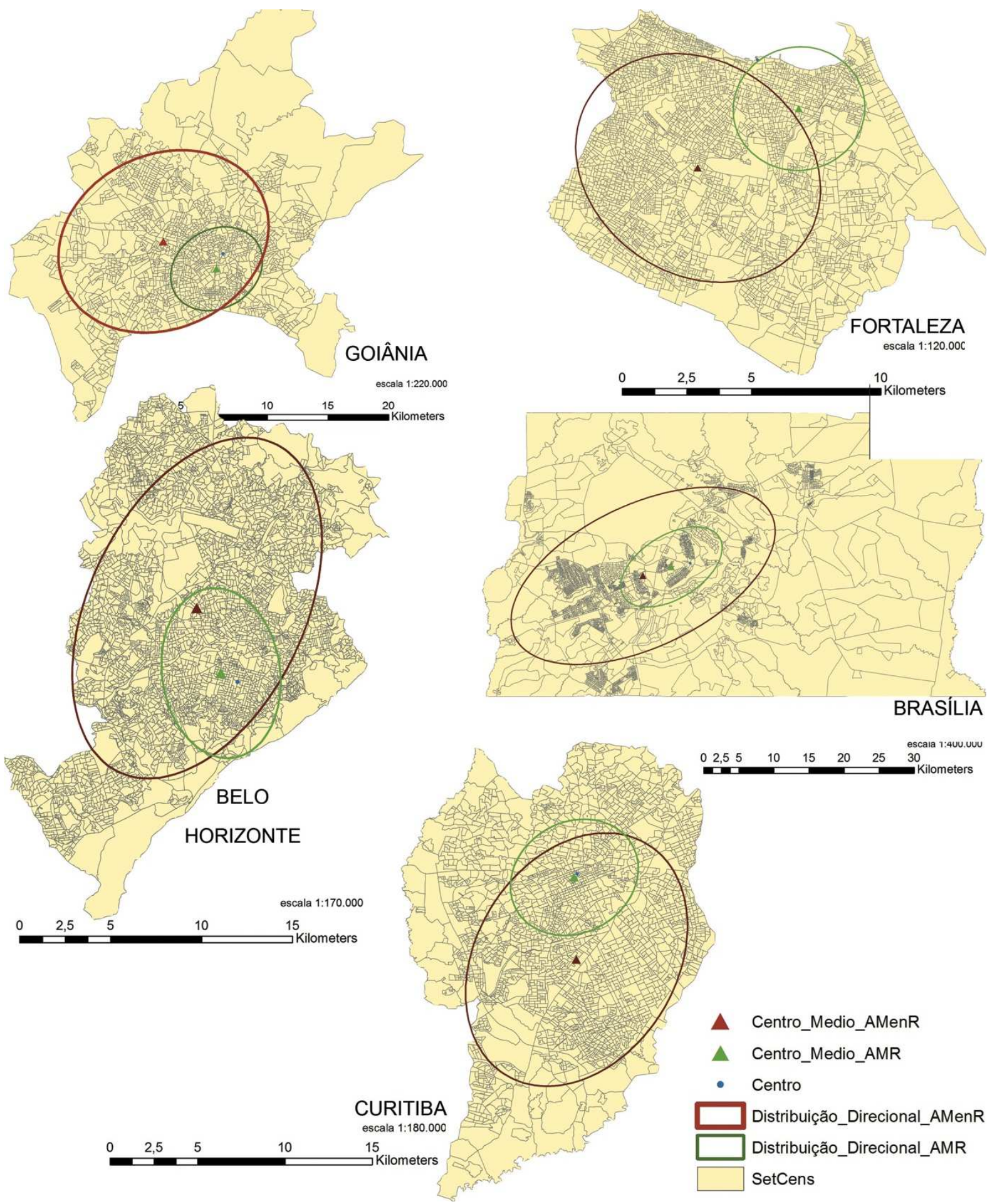

Figura 3 - Método Centrográfico para as cinco cidades estudadas. 


\section{Discussão dos resultados}

Os mapas produzidos com o auxílio de técnicas de AEDE contidos nas figuras 2 e 3 indicam que os dois conjuntos de renda aqui investigados são muito concentrados no espaço de tal modo que podemos apontar para uma situação típica de segregação espacial, fenômeno que é entendido enquanto característica fundamental da produção do espaço urbano singular do capitalismo periférico da cidade brasileira. Isso significa que a produção desta cidade está atrelada à realização da acumulação capitalista cujos objetivos se impõem aos modos de uso do espaço pelas pessoas em geral. Ao produzir o espaço sob a primazia do valor de troca, o uso social da cidade brasileira, produto típico do capitalismo periférico, se enfraquece, estabelecendo as condições para a realização da desigualdade na qual se assenta o funcionamento típico da sociedade brasileira.

Estudos sobre a fragmentação no campo disciplinar da geografia desenvolvida no Brasil entendem-na como uma forma espacial de desigualdade no sentido como o desenvolvido por Carlos (1998) para quem a fragmentação é o produto de uma atividade dividida que ocorre enquanto produto do conflito entre o processo de produção da cidade, que é sempre um esforço conjunto de toda a sociedade e a sua apropriação por parte de poucos indivíduos. Porém, neste trabalho, buscaremos ajustar o poder explicativo deste atributo espacial dando-lhe conotação morfológica.

Segundo Holanda (2010), o lugar é um sistema de barreiras e permeabilidades ao movimento, de cheios e vazios, impregnados de práticas sociais. Interessa-nos as relações entre tais sistemas e expectativas sociais específicas sendo que estas dizem respeito a um sistema de encontros e esquivanças, de concentração e dispersão de pessoas. Holanda sustenta que vasta evidência empírica aponta para uma congruência histórica entre configurações arquitetônicas e urbanas e sistemas sociais, fazendo a ressalva que, apesar de relacionadas, arquitetura e pessoas são, por certo, coisas distintas e que falar em congruência não é falar em determinação biunívoca entre arquitetura e comportamento social, mas é reconhecer que a arquitetura urbana ou edilícia cria um campo de possibilidades e restrições ao movimento que podem - ou não - ser superadas.

Uma compreensão mais acurada da relação entre desigualdade e espaço na cidade brasileira, dadas as particularidades da constituição dos seus arranjos interpartes, não pode 
prescindir da investigação acerca da morfologia urbana, ainda que esta categoria não acompanhe tradicionalmente as análises socioeconômicas explicativas da dinâmica social da segregação urbana.

A intensa fragmentação do território é típica da grande cidade brasileira e se deve, em grande medida, ao processo cotidiano de crescimento dos perímetros urbanos dos municípios a custa da massiva e constante conversão de áreas rurais em novos parcelamentos urbanos com o caráter meramente especulativo. O vetor preferencial desta formação se dá ao longo de rodovias convertidas a avenidas urbanas, mas que mantêm várias características típicas do trânsito rodoviário pesado e acabam por funcionar mais como verdadeiras cunhas nestes tecidos urbanos do que como suporte para uma microeconomia local baseada no movimento peatonal típico de vizinhanças consolidadas e dotadas de vitalidade urbana.

Estas áreas desenvolvidas ao longo destes poucos eixos estruturantes, que penetram o tecido urbano, implicam em um padrão de desenvolvimento excessivamente radial das cidades, de modo que estas acabam por ocupar extensos territórios formados por sucessões de loteamentos uns após os outros. Os centros médios das Áreas de Menor Rendimento (AMenR) marcados nos mapas das figuras 2 e 3 estão sempre muito próximos de importantes trechos urbanos de rodovias que se firmam como as únicas estruturas morfológicas capazes de estruturar minimamente o espaço adjacente, de conjuntos de vazios urbanos ou de uma combinação das duas situações.

No caso de Goiânia, temos a combinação da proximidade do centro médio da AMenR tanto das vias BR 060 e GO 060 e 070 quanto do fundo de vale do ribeirão Anicuns, que marca um claro limite entre o tecido urbano mais contínuo e aquele que contém os setores censitários com domicílios com renda per capita mais baixa e que é descontínuo.

Para Fortaleza, temos a combinação da proximidade das vias CE 060 e 065, do aeroporto internacional e da BR116, que ao atravessar grande parte da cidade marca a divisão entre a região leste com maior quantidade de famílias pertencentes à AMR e a região oeste com maior quantidade de famílias pobres.

Para Belo Horizonte, o centro médio da AMenR próximo ao campus da Universidade Federal de Minas Gerais, vizinho ao Anel Rodoviário, com a posição e a abrangência da elipse 
indicando a ligação entre duas regiões concentradoras de famílias muito pobres. Uma localizada em uma área fragmentada do tecido principal entre o Parque Ecológico e Cultural Jardim das Nascentes e o Anel Rodoviário e a segunda marcada pelo Anel Rodoviário funcionando como elemento separador entre duas regiões com rendas per capita diametralmente opostas. Há ainda um bolsão importante de domicílios de baixa renda per capita na região noroeste cercada pela Lagoa da Pampulha, pelo aeroporto e pela MG-424

No caso de Brasília, A direção da elipse da AMenR é influenciada pela presença de grandes loteamentos do lado oeste da via chamada EPIA (Guará, Águas Claras, Taguatinga, Ceilândia etc.). Já a AMR se encontra confinada no espaço delimitado por duas grandes vias: a EPIA e EPCT, sendo que esta é marcada por grandes vazios, como por exemplo o existente entre a Península Norte e a via que marca os arredores do Jardim Botânico.

Para Curitiba, o centro médio da AMenR está localizado próximo à rodovia Régis Bittencourt, que marca divisão clara na cidade, de modo que a direção da diagonal maior da elipse da AMenR acompanha a inclinação da rodovia. Contudo, a maior concentração das residências mais pobres se dá entre as franjas do município e as vias Contorno Sul e Contorno Leste, que também marcam regiões fragmentadas do sistema urbano.

Os loteamentos destas regiões são projetados e implantados de forma independente da cidade existente, sem cuidado em estabelecer um tipo de continuidade física coerente tanto com o tecido mais central e contínuo quanto com os demais assentamentos próximos previamente existentes (que, por sua vez, também foram criados sem levar em consideração o tecido urbano preexistente) de forma que funcionam como um padrão morfológico de elevada fragmentação.

Esta morfologia gera a descontinuidade dos tecidos em função do desencontro das vias dos diferentes assentamentos adjacentes uns aos outros formando articulações em " $T$ " ou " $\mathrm{L}$ " o que aumenta o caráter labiríntico dos sistemas, em detrimento de articulações em " $X$ ", que, em tese, garantem maior continuidade espacial. O caráter labiríntico é potencializado ainda pelo caráter homogêneo e monótono das paisagens periféricas marcadas por sucessões de casas precárias ou conjuntos habitacionais de baixa qualidade espacial, sendo, portanto, uma situação que garante legibilidade espacial dos diferentes fragmentos especialmente baixa 
A morfologia resultante, bastante comum nas grandes cidades do Brasil (a ponto de podermos debater se se trataria de uma configuração urbana tipicamente brasileira) cria uma barreira adicional ao movimento dos moradores em direção às localidades concentradoras dos melhores estoques de emprego, facilidades e renda da cidade justamente por se tornarem áreas pouco integradas ao conjunto do sistema urbano.

A questão morfológica, assim, importa porque o atributo de fragmentação, que implica baixa integração tanto com as áreas mais afluentes quanto com as áreas vizinhas, impede a existência de um conjunto significativo de vias urbanas contínuas o suficiente se entrecruzando e também estabelecendo ligações hierarquicamente importantes com os trechos urbanos das rodovias em várias direções, tornando-se capazes tanto de ligar essas localidades entre si quanto a outras partes mais distante, como o centro da cidade por exemplo.

O resultado é uma estrutura espacial fraca, que falha enquanto suporte para movimentos locais de pedestres fortes o suficiente de modo a engendrar vitalidade na microeconomia local, nos espaços públicos dos bairros, e falha também em gerar subcentralidades razoavelmente importantes fora da região do centro expandido, que corresponde, grosso modo, à Área de Maior Rendimento (AMR). Neste sentido, inferimos que a morfologia resultante da evolução particular destas regiões tem influência na baixa capacidade que elas têm de forjar emprego e renda razoáveis, melhor rede de serviços, espaços de lazer e participação política e social.

A esse atributo do espaço junta-se outro que também é muito comum em certas regiões das periferias das grandes cidades do país que é a formação de vazios urbanos entre estas e outras partes mais contínuas e densas; situação que contribui decisivamente para apartar regiões inteiras umas das outras dificultando ainda mais o movimento interpartes. A formação destes vazios está ligada à própria lógica mercadológica da formação dos estoques de terra e produção de conjuntos habitacionais por parte do mercado.

A fragmentação resultante em conjunto com a formação dos vazios urbanos forma uma morfologia típicas das áreas ilustradas nas manchas LL dos mapas da figura 2. Esta forma de separação cria novas linhas de divisão que reforçam aquelas socialmente já existentes gerando uma situação que poderíamos chamar de armadilha da espacialização da pobreza, 
que intensifica diversas situações como a baixa na qualidade de vida, a falta de interação social, altas taxas de criminalidade e até maior disparidade de gênero, uma vez que mulheres (em geral, negras) arrimos de família têm, muitas vezes, menor propensão a se deslocarem longas distâncias por medo de certos tipos de crimes e também para permanecerem próximas aos filhos.

De acordo com Santos (2009), a fragmentação isola os mais pobres justamente por causa de imobilidade, o que, de seu ponto de vista, transforma a cidade em um conjunto de guetos podendo levar à desintegração. Esta fragmentação se transforma efetivamente em segregação das classes mais baixas quando localizadas na periferia das grandes cidades. Este dado é relevante porque no Brasil não é raro que bolsões populacionais muito pobres se localizem no centro de grandes cidades. O Rio de Janeiro é um caso exemplar, embora não único em que há proximidade espacial entre classes com uma enorme distância socioeconômica. Logo, para compor o quadro de segregação, o atributo da periferização precisa estar relacionado com o atributo da fragmentação.

A periferização é profundamente espacial, mas não necessariamente morfológica. Segundo Vasconcelos (2013), ela substitui na literatura das ciências sociais brasileira o termo "marginalidade", que, ao se transformar coloquialmente em sinônimo para delinquente, ficou mais associado ao indivíduo do que ao espaço. O termo "periférico" costuma aparecer referenciando a díade "centro-periferia" e é associado, no Brasil, à ideia de pobreza e desigualdade. Portanto, a periferização por si só não indica situação de segregação, mas, antes, indica a condição dos mais pobres na luta pelas localizações na cidade pois a dinâmica urbana tipicamente capitalista os exclui das áreas mais centrais - valiosas para o mercado imobiliário - de modo que lhes sobram as áreas em volta da área de expansão das classes mais ricas, embora não necessariamente contíguas a esta.

Outro aspecto caracterizador da segregação nas grandes cidades brasileiras é que se tratam, muitas vezes, de sistemas urbanos cujas implicações sociais, econômicas, políticas, culturais, ecológicas etc. transcendem, em muito, os limites dos próprios municípios. Segundo relatório da ONU-HABITAT, todas as cidades analisadas aqui fazem parte de arranjos que assumem a forma de cidades-regiões (Fortaleza, Belo Horizonte, Brasília e Curitiba) ou corredores urbanos (Goiânia - Brasília). Esses arranjos formam unidades espaciais, que estão unidas por sistemas de diversas naturezas, acabando por funcionar como motores da 
economia regional, nacional e global em conjunto com outras espalhadas por todos os países. Refletem os vínculos que surgem entre a expansão urbana e os novos modelos da atividade econômica, o que, não raras vezes, resultam em um desenvolvimento regional e urbano desequilibrado.

Não é, portanto, descabido, inferirmos que as grandes desigualdades socioeconômicas percebidas nessas cidades estejam também relacionadas, de alguma maneira, com os novos papeis competitivos desempenhados na rede urbana global. Uma particularidade desses novos arranjos espaciais é a variedade de novas disposições de moradia e trabalho fora da cidade propriamente dita, em cidades satélites ou dormitório, em bairros suburbanos, bairros murados, fragmentos ligados basicamente à rodovia ou ao aeroporto etc.

A expansão espacial desses aglomerados é motivada, além da preferência ou necessidade dos moradores prontamente atendida pelo mercado imobiliário, pela crise de regulamentação, controle e planejamento do parcelamento dos solos, por novas tecnologias e serviços melhores e mais amplos de mobilidade para que as pessoas que moram fora da cidade possam viajar todos os dias até o trabalho no centro urbano. A essa dinâmica podemos chamar de dispersão urbana, que não é apenas o tradicional sprawl típico dos subúrbios estadunidenses do pós-guerra. Essa dispersão vai mais longe, formando, de acordo com Vasconcelos (2013) uma "nova fronteira", para além dos subúrbios típicos, engendrando novos centros de trabalho e residência.

No Brasil, provavelmente, o caso mais emblemático é o de Brasília, como explicam Holanda et al (2008), que embora guarde grandes semelhanças com as demais grandes cidades brasileiras no que tange às mazelas sociais, tem na sua dispersão fortemente dependente de um sistema viário difuso um elemento complicador a mais.

As análises feitas das cinco cidades mais desiguais do Brasil, segundo relatório da ONUHABITAT, utilizando técnicas de autocorrelação espacial global e local e de análise centrográfica produzem evidências que corroboram as explicações acerca da segregação da grande cidade brasileira elencadas neste trabalho. Inferimos que o I de Moran local aponta para padrões constantes para as cinco cidades, enquanto o método centrográfico realça a unicidade da evolução urbana enquanto processo histórico próprio de cada uma das cinco cidades. 
A figura 2 mostra que todas as cinco cidades conhecem clusters pertencentes aos dois grupos de renda estudados. Aquele representado pela mancha $\mathrm{HH}$ forma de uma espécie de casulo a envolver tanto o ponto adotado como central quanto o centro médio da AMR, o que indica a baixa propensão deste grupo abandonar a região central das cidades ou de desenvolver algum vetor de expansão das regiões de moradia que rompam a duradoura ligação com a região central. Desta maneira, podemos falar de um centro expandido típico, que acaba por concentrar - à medida que a cidade se desenvolve - serviços, funcionalidades, comércios, empresas e empregos voltados para as classes mais altas formando uma região com suas partes razoavelmente pouco fragmentadas muito bem conectadas entre si e com a região central.

Nas Áreas de Maior Rendimento (AMR), o valor de uso das localidades é atrelado ao valor de troca por meio do mecanismo de valorização do solo explicitado por Villaça (2007), que garante aos seus proprietários das áreas que a posse de uma localidade dentro do centro expandido funcione como um ticket que dá acesso a toda a cidade, como se esta fosse um sistema de recursos utilizado para a reprodução social de uma classe específica, embora produzida socialmente.

Já o cluster representado pela mancha LL não repete nenhum padrão de distribuição espacial, mas todos são periféricos e coincidem com as áreas mais fragmentadas e, deste modo, desconectadas do tecido mais denso e contínuo das cidades. A figura 3 mostra que os centros médios da elipse representativa das AMenR estão sempre muito próximos de grandes infraestruturas rodoviárias o que mostra a proximidade dos loteamentos ou ocupações regulares ou não voltados para as famílias de renda per capita mais baixa dos grandes eixos de transporte rodoviário convertidos para vias urbanas.

Nas Áreas de Menor Rendimento (AMenR), o valor de uso da terra é, em regra, descolado do valor de troca o que amplia a condição de mera mercadoria. O mercado imobiliário produz inúmeras localidades praticamente indistintas nessas áreas e a homogeneidade e baixo valor das localidades resultantes facilita sua divisão e venda em pedaços sem preocupar com o papel destes lugares dentro da cidade. O espaço segregado (fragmentado, disperso e periferizado) tem pouco a oferecer no esquema de hierarquização dos lugares dentro do município, uma vez que conta com pouquíssimas funções que não aquelas de 
mercadoria e estoque de contingente populacional (excedente?) determinada pela divisão capitalista do trabalho.

Temos também a presença, em maior ou menor quantidade, em todas as cidades analisadas, de algumas regiões ( $\mathrm{LH}$ e $\mathrm{HL}$ ) que apresentam moradias pertencentes aos dois extremos de renda convivendo em relativa proximidade, mas essa realidade não chega a formar um padrão, de modo que em Goiânia, por exemplo, temos uma grande área do tipo LH em volta da mancha $\mathrm{HH}$. O que percebemos é que todas as cidades têm a região que aqui chamamos de "centros expandidos" envolvida completamente por uma área cuja leitura estatística do I de Moran local marcou como "não relevante", ou seja, não havia casos suficientes de moradias afluentes ou muito precárias para que apontasse um processo de clustering, indicando que considerável parcela da grande cidade brasileira é formada por uma periferia mais ou menos fragmentada composta por uma miríade de tipos edilícios habitados por uma população de renda mediana (ainda que em termos absolutos seja uma renda per capita familiar baixa).

Se os mapas da figura 2 indicam padrões espaciais que aproximam as cidades estudadas, 0 mapa 3 realça suas diferenças, mostrando que processos históricos particulares ajudaram a moldar a formação das áreas segregadas. Há dois padrões espaciais importante que podemos extrair dos mapas da figura 3 que dizem respeito à grande concentração da AMR em volta do ponto central e a relativa concentração das AMenR, que pode ser explicada pelo fato de que como estas últimas estão relacionadas com as áreas mais fregmentadas da cidade é natural que esse grupo não se espalhe uniformemente por todo o sistema urbano.

Os mapas da figura 3 apontam para um limite importante dos esquemas explicativos concentrados apenas nos processos socioeconômicos clássicos na literatura brasileira. As diversas maneiras como as elipses das AMenR se distribuem no território indicam, ao nosso ver, que processos históricos da evolução urbana de cada cidade precisam ser trazidos para a análise para o pleno entendimento de como a segregação espacial se formou em cada uma delas. No caso de Goiânia, por exemplo, a cidade mais desigual do país só pode ter o processo formador da segregação da sua área mais pobre efetivamente compreendido a partir do processo histórico de formação, nos anos 1970, de um importante movimento articulado de luta popular pela moradia, que alcança a condição de conflito aberto entre 
população e estado, com a ocupação de fazendas da região noroeste da cidade o dá o início da ocupação da região que a figura 3 indica como AmenR.

Por fim, é preciso também compreender que todo o processo descrito neste estudo não pode ser assimilado, conforme explica Carlos (2013), sem alusão ao processo histórico da urbanização do país que se realiza em um quadro de dependência em relação às economias centrais. As enormes metrópoles latino-americanas se dão no processo de aceleração da urbanização decorrente de uma industrialização poupadora de mão de obra, com altas taxas de exploração da força de trabalho e com extrema concentração de riqueza. Esse encadeamento deixa à margem um contingente populacional que encontrará moradia apenas em locais acessíveis às suas rendas irrisórias (periferização) ou localidades criadas em antigas áreas rurais para além da periferia existente e de locais inúteis (fundos de vales, encostas, alagadiços etc.) para o mercado formal de terras (fragmentação). Nos casos mais extremos da vulnerabilidade social, certos grupos encontrarão moradia em lugares que conjugam perversamente as duas características.

\section{Considerações Finais}

Ao discutirmos a relação entre espaço construído e desigualdade social, com a ajuda das ferramentas de análise espacial, compreendemos, em uma sintonia mais fina, os padrões e tendências da segregação das classes sociais indicando um padrão espacial típico da grande cidade brasileira, estabelecido pela conjugação de três atributos espaciais, a fragmentação e a dispersão do tecido urbano e a periferização de diversos fragmentos.

Importante notar que esses atributos são o resultado de uma forma peculiar de desenvolvimento urbano que associa as condicionantes socioeconômicas presentes na especulação e na primazia do valor de troca da terra urbana em detrimento de seu valor de uso traduzidas na produção social do espaço com a apropriação das localidades de maior acessibilidade por parte das famílias mais ricas, com a matriz de sociabillidade herdada de séculos de escravidão, que deste sempre dividiu a população brasileira entre aqueles que vivem nos sobrados e os que vivem nos mucambos, para usar a célebre figura elaborada por Gilberto Freyre. 
A despeito de a segregação, enquanto dinâmica espacial resultante da desigualdade de renda, ser entendida, em regra, de modo uniforme como resultado apenas de dinâmicas socioeconômicas, as análises trazidas aqui mostram que os estudos sobre desigualdade e segregação nas cidades brasileiras deveriam levar em consideração a morfologia urbana como um componente importante do problema.

Ainda que os dados não apontem para um "efeito gueto", o processo de evolução urbana das cidades brasileiras aponta uma intensa segregação dos mais pobres em algumas áreas da cidade. O caráter da segregação neste caso está em que ao longo da história os mais pobres foram empurrados para áreas com baixo acesso a equipamentos coletivos e, principalmente, baixa integração com o restante da cidade.

Assim, apesar de alguma melhora dos indicadores sociais brasileiros nos últimos anos, as grandes cidades brasileiras seguem sendo cidades segregadas, sobretudo no que diz respeito às suas regiões centrais, melhor integradas e às camadas de mais alta renda que buscam estas localidades que propiciam melhores condições para sua reprodução social. Ressalta-se a ausência de dados mais desagregados no nível dos setores censitários, o que dificulta investigações mais profundas neste sentido.

As políticas públicas da década de 2000 foram relativamente exitosas no enfrentamento das desigualdades de renda, especialmente entre os setores mais pobres, contudo apontamos que o componente espacial da desigualdade é, em parte, responsável pela permanência desta dinâmica social. Isso se deve ao simples fato que distribuição de renda em si não resolve problemas urbanos crônicos como habitação, transporte público ou integração aos recursos do restante da cidade.

Aos espacializarmos os dados, percebemos que certas regiões que combinam graus diferentes de fragmentação, dispersão e periferização parecem exercer um papel importante na reprodução da pobreza tornando-a estrutural. A ausência de políticas públicas mais profundas de reforma urbana buscando integrar fisicamente regiões segregadas ao restante das cidades contribui para a manutenção da condição de pobreza de seus habitantes, enquanto que nos espaços centrais das cidades, onde é possível desfrutar de infraestrutura, acessibilidade e integração está restrita, em grande medida, aos grupos tradicionalmente privilegiados em termos de renda. 


\section{Referências bibliográficas}

BAILEY, Trevor C.; GATRELL, Anthony C. Interactive spatial data analysis. 1a ed. Essex: Prentice Hall. 1995. ISBN 978-05-82244-93-1

CARLOS, Ana F.A. A natureza do espaço fragmentado. In: SANTOS, M.; SOUZA, M. A.; SILVEIRA, M.L. (Org.) Território: globalização e fragmentação. São Paulo: Hucitec, DL, 1998, p. 191-197.

CARLOS, Ana F.A. A prática espacial urbana como segregação e o "direito à cidade" como horizonte utópico. In: VASCONCELOS, Pedro de A; CORRÊA, Roberto L; PINTAUDI, Silvana M (Org.) A cidade contemporânea segregação espacial. São Paulo: Contexto, DL 2013, p.95-109

CORRÊA, Roberto L. Segregação residencial: classes sociais e espaço urbano. In: VASCONCELOS, Pedro de A; CORRÊA, Roberto L; PINTAUDI, Silvana M (Org.) A cidade contemporânea - segregação espacial. São Paulo: Contexto, DL 2013, p.39-59.

FREYRE, Gilberto. Sobrados e mucambos. 5a ed. São Paulo: Global. 2003. ISBN 85-260-0835-8

GENOVEZ, Patrícia C. 2002. Território e desigualdade: Análise Espacial intra-urbana no estudo da dinâmica exclusão/inclusão social no espaço urbano em São José dos Campos - SP. MS thesis, Instituto Nacional de Pesquisas Espaciais de São José dos Campos.

GREENE, Richard; PICK, James. 2a ed. Exploring the urban community: A GIS approach. New Jersey: Prentice Hall. 2012. ISBN 13-978-0-321-75159-1

HOLANDA, F. de. Brasília. Cidade moderna cidade eterna. 1ạ ed. Brasília: Editora UnB. 2010. ISBN 978-8560762-02-6

HOLANDA, Frederico, RIBEIRO, Rômulo, MEDEIROS, Valério. Brasília, Brazil: economic and social costs os dispersion. In International Society of City and Regional Planners, 44, Dalian, 2008, Dalian - China: Dalian Publishing House. p 1-12. ISBN 978-90-75524-58-1

Instituto Brasileiro de Geografia e Estatística, 2011. Base de informações do Censo Demográfico 2010: Resultados do Universo por setor censitário. Rio de Janeiro: IBGE.

LEFEVBRE, Henri. O direito à cidade. 5ạ ed. São Paulo: Centauro. 2011. ISBN 978-85-88208-97-1

MARICATO, Ermínia. Brasil, cidades: alternativas para a crise urbana. 2a ed. Petrópolis: Vozes. 2002. ISBN 85326-2633-5

MITCHELL, Andy, 2009. GIS analysis - Spatial measurements \& statistics. Redlands: Esri Press.

OLIVEIRA, Francisco. Crítica à razão dualista o ornintorrinco. 1a ed. São Paulo: Boitempo. 2003. ISBN 978-857559-036-2

RAMOS, Frederico R 2002. Análise espacial de estrutura intra-urbanas: o caso de São Paulo. MS thesis, Instituto Nacional de Pesquisas Espaciais de São José dos Campos.

SABATINI, F., SIERRALTA, C. Medição da segregação residencial: meandros teóricos e metodológicos e especificidade latino-americana. In: CUNHA, J.M.P. (Org.). Novas metrópoles paulistas: população, vulnerabilidade e segregação. Campinas: Nepo/Editora da Unicamp, DL 2006, p.170-195.

SANTOS, Milton. Metrópole corporativa fragmentada: o caso de São Paulo. 2009. ISBN 878 -85-314-1159-5

SOARES, Sergei. Desigualdade de renda. In: CASTRO, Jorge, VAZ, Fábio (Org.). Situação social brasileira: monitoramento das condições de vida. Brasília: IPEA, DL 2011, p.

United Nations Human Setlements Programm. State of the world's cities 2010/2011 - Bridging the urban divide. Londres: UN-HABITAT. 2012. ISBN 978-1-84971-176-0 
VASCONCELOS, Pedro A. Contribuições para o debate sobre processos e formas socioespaciais nas cidades. In: VASCONCELOS, Pedro de A; CORRÊA, Roberto L; PINTAUDI, Silvana M (Org.) A cidade contemporânea segregação espacial. São Paulo: Contexto, DL 2013, p.17-37

VILLAÇA, Flávio. Espaço intra-urbano no Brasil. 2ª ed.. São Paulo: Studio Nobel. 2007. ISBN 978-85-85445-75-1 